\title{
Glucagonoma and the glucagonoma syndrome (Review)
}

\author{
XUJUN SONG ${ }^{*}$, SULI ZHENG ${ }^{*}$, GANG YANG ${ }^{*}$, GUANGBING XIONG, \\ ZHE CAO, MENGYU FENG, TAIPING ZHANG and YUPEI ZHAO
}

\begin{abstract}
Department of General Surgery, Peking Union Medical College Hospital, Chinese Academy of Medical Sciences and Peking Union Medical College, Beijing 100730, P.R. China
\end{abstract}

Received September 12, 2016; Accepted August 17, 2017

DOI: $10.3892 / \mathrm{ol} .2017 .7703$

\begin{abstract}
Glucagonoma is an extremely rare pancreatic $\alpha$-islet cell tumor and is often accompanied by certain clinical symptoms including necrotizing migratory erythema (NME), diabetes, weight loss and anemia. The objectives of the current review were to discern the clinical features, diagnosis, treatment and prognosis of glucagonoma by evaluating 623 reported cases. A 1998 study reviewed 407 cases and 216 cases were reported in studies published after 1998. The current review consisted of 268 males and 339 females, with an average age of 52.4 years. The male-to-female ratio was 0.79 . The incidence of typical clinical findings were as follows: NME, 82.4\% (350/425); diabetes, 68.5\% (291/425); weight loss, 60.2\% (256/425); anemia, 49.6\% (211/425); and glossitis or stomatitis or cheilitis, $41.2 \%(175 / 425)$. A total of 499 cases reported the location of the tumor as the pancreas and $64.1 \%$ (320/499) involved the pancreatic tail. Tumor size was recorded in 58.3\% (126/216) cases reported after 1998 and average tumor size was $5.0 \mathrm{~cm}$. Metastasis was detected in $49.2 \%$ of patients $(293 / 595$ for whom metastasis or no metastasis were recorded) upon diagnosis. These patients were older than those without metastasis (average age, 54.0 years old vs. 50.8 years old). The average time between symptoms and diagnosis of glucagonoma was 31.4 months. Glucagonoma is a very rare disease. It is important for clinicians to learn more about this disease to be able to diagnose and treat it as early as possible, thus improving patient prognosis.
\end{abstract}

Correspondence to: Professor Taiping Zhang or Professor Yupei Zhao, Department of General Surgery, Peking Union Medical College Hospital, Chinese Academy of Medical Sciences and Peking Union Medical College, 1 Shuaifuyuan Wangfujin, Beijing 100730, P.R. China

E-mail: tpingzhang@yahoo.com

E-mail: zhao8028@263.net

*Contributed equally

Key words: glucagonoma, glucagonoma syndrome, necrotizing migratory erythema, diabetes mellitus, diagnosis

\section{Contents}

1. Introduction

2. Methods

3. Characteristics of included studies

4. Demographic data

5. Clinical manifestation

6. Location and size of the tumor

7. Metastatic disease

8. Prognosis

9. Discussion

\section{Introduction}

Glucagonoma is a very rare disease and its incidence rate is 2.4/100,000,000 in America (1) and 2.6/100,000,000 in Japan (2). According to the World Health Organization (WHO) classification of tumors of the digestive system, glucagonoma is a type of functional pancreatic neuroendocrine neoplasm (pNEN) (3). Surgery is currently the only method of curing glucagonoma. Somatostatin analogues (SSA) and amino acid solution infusion may result in the rapid relief of symptoms (4). Transarterial chemoembolization, radiation therapy and peptide receptor radioligand therapy may also be useful treatments $(4,5)$.

This pancreatic neuroendocrine tumor (pNET) secretes glucagon and causes a combination of symptoms known as glucagonoma syndrome (5). These symptoms include the skin disorder necrolytic migratory erythema (NME), diabetes mellitus, stomatitis, weight loss and anemia (6). Glucagonoma is generally diagnosed when blood glucagon levels are elevated and should be distinguished from non-functional pancreatic $\alpha$-cell tumors. Patients who have glucagonoma syndrome and elevated glucagon levels may be diagnosed with glucagonoma (7).

In 1942, Becker et al (8) were the first to document an erosive cutaneous eruption in a patient with diabetes mellitus and pancreatic islet cell tumor. McGavran et al (9) identified elevated glucagon levels in the blood and tumor tissue of a patient with diabetes mellitus, NME and a pancreatic tumor. Wilkinson (10) first hypothesised that there may be an association between NME and glucagonoma in his report of a patient with pancreatic carcinoma. NME is a superficial epidermal necrosis characterized by spontaneous remissions or relapse, and it is the first symptom in $\sim 70 \%$ of all patients 
with glucagonoma (5). NME may be painful or itchy, and is often superinfected (7).

Numerous sporadic cases and several small case series $(5,11)$ have been documented. The largest case series were reported by Kindmark et al (11) in 2007, including 23 patients diagnosed with a glucagon-producing NET. In 1998, Soga and Yakuwa (6) evaluated 407 reported cases, including 138 cases documented in Japan. The aim of the present study was to evaluate cases of glucagonoma documented before and after 1998 to help clinicians learn more about this rare disease and improve its diagnosis. The information of patients with glucagonoma prior to 1998 were extracted from a study by Soga and Yakuwa (6) as there are 138 cases documented in Japanese and a number of them were not published in English.

\section{Methods}

Literature search. A literature search was conducted using the following search strategy: Glucagonoma OR (((hyperglucagonemia OR (secreting AND glucagon)) AND (pancreatic AND (((tumor OR Neoplasm) OR cancer) OR carcinoma))). Information was obtained through PubMed (12) and the Wanfang Standards Database (http://www.wanfangdata.com.cn/), as well as from the references of relevant articles. In the current review, 173 published reports describing 216 cases of glucagonoma after 1998 were reviewed. Information regarding cases before 1998 was obtained from an evaluation of 407 glucagonomas published in 1998 by Soga and Yakuwa (6). This article included 138 cases in Japan and information regarding other cases that were not published in English or Chinese. Articles were evaluated and data were extracted separately by two different authors.

Inclusion and exclusion criteria. Studies were included in the current review if they met the following criteria: Patients had been diagnosed with glucagonoma by pathology or patients who had glucagonoma syndrome and elevated blood glucagon levels simultaneously; the article included some patient data, including patient age, sex and clinical symptoms.

Studies were excluded if: They were a duplicate publication; they were published in languages other than English or Chinese and there were no data obtainable from the title and abstract to be evaluated; they included no data pertaining to patients with glucagonoma; and if the articles were inaccessible, meaning that data were unobtainable.

\section{Characteristics of included studies}

A literature search was performed using the aforementioned search strategy. A total of 80 glucagonoma cases were documented in articles published in Chinese after 1998 and 66 cases that met the inclusion criteria were included. A total of 1,343 articles that were published in a language other than Chinese were identified in PubMed as relevant. There were 647 articles and 454 cases of glucagonoma mentioned after 1998 and 150 cases were included. A total of 224 cases were excluded because they were mentioned in articles about pNET or in articles evaluating glucagonoma samples that didn't include the required patient information. A total of 41 cases after 1998 were excluded as they were not published in English or Chinese and the information were inaccessible. A total of
39 cases were excluded as the article could not be accessed and the data were unobtainable. Therefore, 216 cases documented after 1998 were included in the current review. Information regarding cases before 1998 was obtained from the article by Soga and Yakuwa (6), which included information regarding 138 cases in Japan and other cases that were not published in English or Chinese.

The cases included in the current review consisted of patients diagnosed with glucagonoma before and after 1998 following comprehensive consideration of multiple criteria, including clinical symptoms, blood glucagon levels, presence of the tumor, results from pathological and immunohistochemical staining. Furthermore, since patients with glucagonoma and non-functional pancreatic $\alpha$-cell tumors exhibit similar symptoms, cases could have included patients with either disease.

\section{Demographic data}

A total of 534 cases of glucagonoma were documented in articles published between January 1998 and March 2016. Out of these cases, 216 were reviewed in the current study, including 66 cases reported in Chinese. Soga and Yakuwa (6) documented 407 cases; therefore, to the best of our knowledge, the total number of patients with glucagonoma documented in the literature is 941 . Out of all these cases, only 623 out of 941 cases included the relevant patient information. In the old series (papers published prior to the WHO classification of tumors of the digestive system in 2010 (3)), patients with glucagonoma included those with pNET who were positive for glucagon immunohistochemistry, with or without glucagonoma syndrome.

Some cases were excluded as there was not enough data to be evaluated. Papotti (13) referred to samples of five patients with glucagonoma in his basic medical research. In that research, the tumor samples were from a biological sample bank. It is difficult to identify exactly how many cases there were, as these cases referred to in basic medical research may have been reported in the past as case reports. A number of case reports may have been included in case series, meaning that the total number of glucagonoma cases may be lower than that cited in the present review. For example, 'Survival from malignant digestive endocrine tumors in England and Wales: A population-based study' included 17 cases of glucagonoma (14), however it is difficult to determine how many cases had been previously documented.

As presented in Table I, the male-to-female ratio was 0.80 in cases reported after 1998, 0.79 in cases before 1998 and 0.79 overall. Out of the 216 included cases documented in papers published after 1998, 89 were male and 111 were female. Mean age at diagnosis was 52.2 years old (Table II).

There were 268 males and 339 females included in the current review. The average age of the 407 patients documented before 1998 was 52.5 years old. Patient age was reported in 200 of the 216 patients in studies published after 1998 and the average age of these patients was 52.3 years old (Table II).

Overall, 48.5\% (279 of 575 for whom metastasis or no metastasis were recorded) of patients exhibited metastases upon diagnosis. Patients with metastasis were older than those without metastasis (mean age, 54.0 years old vs. 50.8 years old, respectively; Table III). 
Table I. Patient sex and male-to-female ratio.

\begin{tabular}{lcrrr}
\hline & Glucagonoma & Male & Female & Male-to-female ratio \\
\hline Reported before 1998 & 407 & 179 & 228 & 0.79 \\
Reported in and after 1998 & 216 (200 with information on patient sex) & 89 & 111 & 0.80 \\
Overall & 623 (607 with information on patient sex) & 268 & 339 & 0.79 \\
\hline
\end{tabular}

Table II. Average age and age range.

\begin{tabular}{|c|c|c|c|c|c|}
\hline Average age and age range (years) & & Range & Male & Female & Average \\
\hline Reported before 1998 & 407 & $11-88$ & 52.3 & 52.7 & 52.5 \\
\hline Reported in and after 1998 & 216 (200 with data on patient sex) & $15-77$ & 52.2 & 52.2 & 52.2 \\
\hline Total & 623 (607 with data on patient sex) & $11-88$ & 52.3 & 52.5 & 52.4 \\
\hline
\end{tabular}

Table III. Average age, age range (years) and metastasis.

\begin{tabular}{lccrr}
\hline & Range & Reported before 1998 & Reported in and after 1998 & Overall (n=575) \\
\hline With metastases & $19-88$ & $54.3(\mathrm{n}=209)$ & $53.3(\mathrm{n}=70)$ & $54.0(\mathrm{n}=279)$ \\
Without metastases & $11-84$ & $50.6(\mathrm{n}=198)$ & $51.3(\mathrm{n}=98)$ & $50.8(\mathrm{n}=296)$ \\
\hline
\end{tabular}

Table IV. Clinical manifestations.

\begin{tabular}{|c|c|c|c|c|c|c|}
\hline \multirow[b]{2}{*}{ Clinical manifestations } & \multicolumn{2}{|c|}{ Overall $(n=425)$} & \multicolumn{2}{|c|}{$\begin{array}{c}\text { Before } 1998 \\
(n=233 ; 54.8 \%)\end{array}$} & \multicolumn{2}{|c|}{$\begin{array}{c}\text { After } 1998 \\
(\mathrm{n}=192 ; 45.2 \%)\end{array}$} \\
\hline & no. & $\%$ & no. & $\%$ & no. & $\%$ \\
\hline NME & 350 & 82.4 & 198 & 85.0 & 152 & 79.2 \\
\hline Diabetes & 291 & 68.5 & 171 & 73.4 & 120 & 62.5 \\
\hline Weight loss & 256 & 60.2 & 152 & 65.2 & 104 & 54.2 \\
\hline Anemia & 211 & 49.6 & 127 & 54.5 & 84 & 43.8 \\
\hline Glossitis/stomatitis/cheilitis & 175 & 41.2 & 92 & 39.5 & 83 & 43.2 \\
\hline
\end{tabular}

NME, necrotizing migratory erythema.

\section{Clinical manifestation}

When studying the clinical manifestations of glucagonoma, only 233 of the 407 cases before 1998 were included as only this number of cases had diabetico-dematogenic syndrome and were therefore regarded as genuine glucagonoma cases. The other patients of the 407 cases did not have glucagonoma syndrome, thus the tumor is not functioning and should be differentiated from glucagonoma (3). Out of the 216 cases documented after 1998, information regarding the clinical manifestations of glucagonoma in 192 patients was available. This means that there were a total of 425 patients exhibiting clinical manifestations of glucagonoma that could be assessed in the current review. The incidence of typical clinical findings were: NME,
$82.4 \%$ (350/425); diabetes, 68.5\% (291/425); weight loss, $60.2 \%$ (256/425); anemia, $49.6 \%$ (211/425); glossitis or stomatitis or cheilitis, 41.2\% (175/425; Table IV). As presented in Table V, the clinical manifestations of glucagonoma differed between males and females. Out of the 192 cases documented after 1998, the incidence of glossitis or stomatitis or cheilitis or angular cheilitis was $42.4 \%$ (36/85) in males and 67.3\% (72/107) in females. Furthermore, onychodystrophy was only documented in females $(6.5 \% ; 7 / 107)$. Females were also more likely to have NME (82.2 vs. $75.3 \%$ in males), diabetes or impaired fast glucose (IFG) (64.5 vs. $60 \%$ in males), anemia (46.7 vs. $40 \%$ in males), nausea or anorexia (14.0 vs. $8.2 \%$ in males). However, the incidence of weight loss, weakness or fatigue, diarrhea and abdominal pain were higher in males compared with females. 
Table V. Primary clinical manifestations of 192 cases reported in and after 1998.

\begin{tabular}{|c|c|c|c|c|}
\hline \multirow[b]{2}{*}{ Main clinical manifestations } & \multicolumn{2}{|c|}{$\begin{array}{l}\text { Male } \\
(\mathrm{n}=85 ; \\
43.4 \%)\end{array}$} & \multicolumn{2}{|c|}{$\begin{array}{l}\text { Female } \\
(\mathrm{n}=107 \\
56.6 \%)\end{array}$} \\
\hline & no. & $\%$ & no. & $\%$ \\
\hline NME & 64 & 75.3 & 88 & 82.2 \\
\hline Diabetes or IFG & 51 & 60.0 & 69 & 64.5 \\
\hline Weight loss & 50 & 58.8 & 54 & 50.5 \\
\hline Anemia & 34 & 40.0 & 50 & 46.7 \\
\hline Diarrhea & 11 & 12.9 & 8 & 7.5 \\
\hline Abdominal pain & 9 & 10.6 & 8 & 7.5 \\
\hline Angular cheilitis & 8 & 9.4 & 17 & 15.9 \\
\hline Nausea or anorexia & 7 & 8.2 & 15 & 14.0 \\
\hline DVT or pulmonary embolism & 4 & 4.7 & 5 & 4.7 \\
\hline Onychodystrophy & 0 & 0.0 & 7 & 6.5 \\
\hline Neurological symptoms & 9 & 10.6 & 8 & 7.5 \\
\hline Mental symptoms & 9 & 10.6 & 8 & 7.5 \\
\hline Peripheral edema & 5 & 5.9 & 6 & 5.6 \\
\hline Weakness or fatigue & 11 & 12.9 & 7 & 6.5 \\
\hline Glossitis & 16 & 18.8 & 28 & 26.2 \\
\hline Stomatitis & 9 & 10.6 & 22 & 20.6 \\
\hline Cheilitis & 3 & 3.5 & 5 & 4.7 \\
\hline
\end{tabular}

NME, necrotizing migratory erythema; IFG, impaired fast glucose.

Some patients had been reported to be suffering from mental symptoms, including depression (15), poor sleep (16), nervousness (17) and malaise (18). Certain patients exhibited neurological symptoms, including left-sided migraine headache (19), numbness or tingling (18) and Lewy body dementia (20). Some patients experienced vulvovaginitis (21), vomiting, fingernail deformity and fragility (22).

In rare cases, glucagonoma may present as dilated cardiomyopathy, acute pulmonary edema or left ventricular failure $(23,24)$. In one case reported by Chang-Chretien et al (23), a 54-year-old patient had congestive heart failure and sinus tachycardia, with a history of weight loss, sore tongue, brittle nails and dyspareunia. The patient exhibited dilated cardiomyopathy with an ejection fraction of $15 \%$. One year later, the patient developed NME, which led to the suspicion of glucagonoma and the identification of a pancreatic mass. The patient underwent tumor resection and 8 months later, had a normal left ventricular end diastolic dimension $(4.7 \mathrm{~cm})$ and a normal ejection fraction $(55 \%)$. Out of the cases included in the current review, there were also other rare symptoms reported, which included thrombophlebitis (18), pancytopenia (25) and balanitis (26).

\section{Location and size of the tumor}

Table VI presents information regarding tumor location and size. A total of 499 cases reported the location of the tumor as the pancreas and $64.1 \%(320 / 499)$ of these cases involved the tail of the pancreas. Tumor size was recorded in 58.3\%
(126/216) cases reported after 1998. Average diameter was $5.0 \mathrm{~cm}$ and the median tumor size in patients evaluated before 1998 was $3.1-5.5 \mathrm{~cm}$. A study by Shyr et al (27) in 1999 reviewed 120 cases of glucagonoma in the literature and determined that the average tumor diameter was $3.6 \mathrm{~cm}$.

The most common site of the tumor was the tail of the pancreas $(40.1 \%)$, followed by the body and tail $(20.0 \%)$, the head (16\%) and the body (15.4\%). Out of all included cases, the vast majority $610(97.8 \%)$ had glucagonomas in the pancreas; 6 had extrapancreatic lesions and in 8 cases, the original sites were not specified.

\section{Metastatic disease}

The average time from symptom to diagnosis was 31.4 months in 50\% (108/216) of patients evaluated after 1998. Table VII presents information regarding metastasis in patients. Delayed diagnosis of the disease meant that $49.2 \%$ of patients had metastases upon diagnosis. Metastatic disease was identified in $51.4 \%$ of patients reported before 1998 and $44.7 \%$ after 1998 . The liver (80.5\%), lymph nodes (33.1\%) and mesentery/omentum/peritoneum (3.4\%) were the most common sites of involvement in patients with metastases. Tumor involvement also occurred in the lung (2\%) and spleen or the hilus of spleen (2\%).

\section{Prognosis}

There were 105 cases (48.6\% of the 216 cases) reported after 1998 that included information regarding patient prognosis and the average follow up time was 43.2 months. Out of these cases, 26 succumbed and the average survival time was 32.1 months. The longest survival time was 24 years, reported by Nightingale et al (28) in 1999.

\section{Discussion}

Diagnosis of glucagonoma involves glucagonoma syndrome and elevated blood glucagon levels (7). However, these diagnostic criteria are insufficient to diagnose glucagonoma promptly and some patients may be delayed in diagnosis or be misdiagnosed. In old series (published prior to the WHO classification of tumors of the digestive system (3)), glucagonoma included patients with pNET positive for glucagon immunohistochemistry on pathological specimen that did not exhibit specific symptoms (6). Immunoreactive glucagon fractions that exhibit reduced bioactivity are not functioning as the patients do not have glucagonoma syndrome (29). Currently, these patients without glucagonoma syndrome would not be diagnosed with glucagonoma according to the WHO classification of tumors of the digestive system (3). However, it was difficult to make this distinction in the current study, as it is difficult to extract data from the 407 cases included in the study by Soga and Yakuwa (6). Furthermore, patients without any symptoms may still have a tumor in the pancreas and require treatment.

The current study indicated that NME occurs in $80 \%$ of patients with glucagonoma. It may be accompanied by nail dystrophy, conjunctivitis, cheilitis, glossitis or stomatitis. However, skin biopsies are not effective at diagnosing NME. In the 6 cases evaluated by Eldor et al (4), an evaluation of six 
Table VI. Primary lesion sites.

\begin{tabular}{|c|c|c|c|c|c|c|}
\hline \multirow[b]{2}{*}{ Primary site } & \multicolumn{2}{|c|}{ Overall $(n=623)$} & \multicolumn{2}{|c|}{ Before $1998(n=407)$} & \multicolumn{2}{|c|}{ After $1998(n=216)$} \\
\hline & no. & $\%$ & no. & $\%$ & no. & $\%$ \\
\hline Specified in pancreas & 499 & 80.1 & 342 & 84 & 157 & 72.7 \\
\hline Head & 83 & 16.6 & 63 & 18.4 & 20 & 12.7 \\
\hline Neck & 7 & 1.4 & 0 & 0.0 & 7 & 4.5 \\
\hline Body & 77 & 15.4 & 59 & 17.3 & 18 & 11.5 \\
\hline Tail & 200 & 40.1 & 143 & 41.8 & 57 & 36.3 \\
\hline Head and neck & 3 & 0.6 & 0 & 0.0 & 3 & 1.9 \\
\hline Head and body & 8 & 1.6 & 7 & 2.0 & 1 & 0.6 \\
\hline Neck and body & 1 & 0.2 & 0 & 0.0 & 1 & 0.6 \\
\hline Body and tail & 100 & 20.0 & 53 & 15.5 & 47 & 29.9 \\
\hline Head and tail & 4 & 0.8 & 1 & 0.3 & 3 & 1.9 \\
\hline Diffuse & 16 & 3.2 & 16 & 4.7 & 0 & 0 \\
\hline \multicolumn{7}{|l|}{ Overall evaluation } \\
\hline Head & 114 & 22.8 & 87 & 25.4 & 27 & 17.2 \\
\hline Neck & 11 & 2.2 & 0 & 0.0 & 11 & 7.0 \\
\hline Body & 195 & 39.1 & 128 & 37.4 & 67 & 42.6 \\
\hline Tail & 320 & 64.1 & 213 & 62.3 & 107 & 68.2 \\
\hline Not specified in pancreas & 110 & 17.7 & 55 & 13.5 & 55 & 25.5 \\
\hline Extrapancreatic organs & 6 & 1.0 & $3^{\mathrm{a}}$ & 0.7 & $3^{\mathrm{b}}$ & 1.9 \\
\hline Not specified & 8 & 1.3 & 7 & 1.7 & 1 & 0.5 \\
\hline
\end{tabular}

${ }^{\mathrm{a} O n e}$ each in kidney, duodenum, and lung; ${ }^{\mathrm{b}}$ One in duodenum, and two in liver.

Table VII. Metastases: Sites of involvement.

\begin{tabular}{|c|c|c|c|c|c|c|}
\hline \multirow[b]{2}{*}{ Patients with metastases } & \multicolumn{2}{|c|}{$\begin{array}{c}\text { After } 1998 \\
(\mathrm{n}=84 ; 44.7 \%)\end{array}$} & \multicolumn{2}{|c|}{$\begin{array}{c}\text { Before } 1998 \\
(n=209 ; 51.4 \%)\end{array}$} & \multicolumn{2}{|c|}{$\begin{array}{c}\text { Total } \\
(n=293 ; 49.2 \%)\end{array}$} \\
\hline & no. & $\%$ & No. & $\%$ & no. & $\%$ \\
\hline \multicolumn{7}{|l|}{ Metastases sites } \\
\hline Liver & 69 & 82.1 & 167 & 79.9 & 236 & 80.5 \\
\hline Lymph nodes & 18 & 21.4 & 79 & 37.8 & 97 & 33.1 \\
\hline Bone & 6 & 7.1 & 17 & 8.1 & 23 & 7.8 \\
\hline Mesentery/omentum/peritoneum & 0 & 0 & 10 & 4.8 & 10 & 3.4 \\
\hline Lung & 0 & 0 & 6 & 2.9 & 6 & 2.0 \\
\hline Adrenal & 1 & 1.2 & 3 & 1.4 & 4 & 1.4 \\
\hline Gallbladder & 1 & 1.2 & 0 & 0 & 1 & 0.3 \\
\hline Ileal & 1 & 1.2 & 0 & 0 & 1 & 0.3 \\
\hline Spleen or the hilus of spleen & 6 & 7.1 & 0 & 0 & 6 & 2.0 \\
\hline Multiple but not specified & 2 & 2.4 & 0 & 0 & 2 & 0.7 \\
\hline
\end{tabular}

available skin biopsies of the patients with glucagonoma indicated that only one was clearly positive for glucagonoma rash; the others exhibited only non-specific changes. NME may also present in patients without elevated glucagon level. It has been reported in cases of hepatic dysfunction and cirrhosis (30), jejunal and rectal adenocarcinoma and myelodysplastic syndrome (31). In 108 cases documented after 1998, the average time from symptom manifestation to the diagnosis of glucagonoma was 31.4 months. Diagnosis is often delayed, as the disease is extremely rare and as NME is not well known.

In 2015, Gaiser and Dhawan (25) documented a case with a medical history of atrial fibrillation, diabetes mellitus and anemia presenting with pancytopenia. An abdominal computed tomography identified a pancreas mass, with 
four liver metastases. Needle biopsy of the pancreatic mass stained positive for synaptophysin and negative for glucagon. The patient did not exhibit signs of glucagonoma until weeks following a therapy using everolimus. Thus, the results of immunohistochemical staining may not always be consistent with the clinical course of the disease and symptoms of glucagonoma may present late. Indeed, Yamashita (32) reported the case of a patient with a tumor that was clinically an insulinoma but histopathologically a glucagonoma. Demir et al (24) reported a case of glucagonoma in which the patient had acute pulmonary edema and left ventricular failure. Initially, the patient was diagnosed with dilated cardiomyopathy. However, 2 years later, the patient developed a troublesome itch and during subsequent investigations, a pancreatic mass was identified. The patient underwent a distal pancreatectomy and recovered from dilated cardiomyopathy 1 month following surgery. Lolis et al (33) reported a case in which a patient developed NME 6 years following diagnosis of a metastatic neuroendocrine tumor. The patient succumbed 2 months after presentation of NME. In certain cases, the typical clinical syndromes of glucagonoma occur too late for diagnosis and may not actually manifest until the patient succumbs.

Fasting plasma glucagon $>500 \mathrm{pg} / \mathrm{ml}$ (normal range, $50-150 \mathrm{pg} / \mathrm{ml}$ ) may be a diagnostic criterion for glucagonoma (34). Mild elevated glucagon levels may be associated with other diseases, including malabsorption, infection or hepatic cirrhosis (35). Glucagon receptor gene mutations may also cause hyperglucagonemia without glucagonoma syndrome (36). Drugs may also cause hyperglucagonemia, for example, Glueck et al (37) reported that estrogen replacement in a protein $\mathrm{S}$ deficient patient caused diarrhea, hyperglucagonemia and osteonecrosis.

In 2010, Vanderlan et al (38) documented the case of a 64-year-old man diagnosed with a duodenal enteroglucagonoma. This patient had hypoalbuminemia, refractory severe hypokalemia, uncontrolled new onset diabetes mellitus, anemia and peripheral edema, as well as low serum glucagon levels. A periampullary mass, which exhibited positive immunohistochemical reactivity to DakoCytomation's Polyclonal Rabbit AntiHuman Glucagon, meaning low glucagon levels, was surgically removed. This indicates that in some cases, an elevated blood glucagon level may not be required to diagnose glucagonoma. However, overdiagnosis may occur due to the identification of immunoreactive glucagon fractions that exhibit reduced bioactivity (29).

The localization of the tumor is very important for diagnosis and treatment. The methods used to localize glucagonoma are similar to methods used to localize other pancreatic neuroendocrine tumors, including ultrasonography, computed tomographic scan and magnetic resonance imaging somatostatin receptor scintigraphy (SRS). The most accurate method is SRS (39) and it is the recommended imaging technique in the localization and staging procedure for patients with glucagonoma (40).

Surgery is currently the only method of curing glucagonoma. Surgical resection with curative intent or debulking procedures may lead to long-term palliation (4). NME may disappear 1 week after surgery. Laparoscopic resection is adequate (41). In patients with hepatic metastases, aggressive concurrent resection of the primary tumor and hepatic metastases is beneficial when it is technically feasible (42).

Somatostatin analogues (SSA) and amino acid solution infusion may lead to the rapid relief of symptoms. Transarterial chemoembolization, radiation therapy, peptide receptor radioligand therapy may also be useful treatments $(4,5)$. In two large case series of glucagonoma, chemotherapy induced a $50 \%$ radiological response $(5,43)$.

The current review indicated that the average time from symptom onset to diagnosis is 31.4 months and demonstrated that $49.2 \%$ patients have metastasis upon final diagnosis. The average age of the diagnosis of glucagonoma was 52.4 years old. The male-to-female ratio was 0.79 . The incidence rates of clinical pathologies commonly associated with glucagonoma were as follows: NME, 82.4\%; diabetes, 68.5\%; weight loss, $60.2 \%$; and anemia, 49.6. $64.1 \%$ of all pancreatic glucagonoma involved the pancreatic tail and the average tumor size was $5.0 \mathrm{~cm} .49 .2 \%$ of patients had metastasis upon diagnosis. It is important for clinicians to learn more about glucagonoma so as to diagnose it as early as possible.

\section{References}

1. Yao JC, Eisner MP, Leary C, Dagohoy C, Phan A, Rashid A, Hassan M and Evans DB: Population-based study of islet cell carcinoma. Ann Surg Oncol 14: 3492-3500, 2007.

2. Ito T, Sasano H, Tanaka M, Osamura RY, Sasaki I, Kimura W, Takano K, Obara T, Ishibashi M, Nakao K, et al: Epidemiological study of gastroenteropancreatic neuroendocrine tumors in Japan. J Gastroenterol 45: 234-243, 2010.

3. Klimstra DS, Arnold R, Capella C, et al: Neuroendocrine neoplasms of the pancreas. In: WHO classification of tumours of the digestive system. Bosman FT, Carneiro F, Hruban RH, Theise ND, (eds.) IARC Press, Lyon, pp322-326, 2010.

4. Eldor R, Glaser B, Fraenkel M, Doviner V, Salmon A and Gross DJ: Glucagonoma and the glucagonoma syndrome-cumulative experience with an elusive endocrine tumour. Clin Endocrinol (Oxf) 74: 593-598, 2011.

5. Wermers RA, Fatourechi V, Wynne AG, Kvols LK and Lloyd RV: The glucagonoma syndrome. Clinical and pathologic features in 21 patients. Medicine (Baltimore) 75: 53-63, 1996.

6. Soga J and Yakuwa Y: Glucagonomas/diabetico-dermatogenic syndrome (DDS): A statistical evaluation of 407 reported cases. J Hepatobiliary Pancreat Surg 5: 312-319, 1998.

7. Anne Couvelard and Olivia Hentic: Glucagonoma. In: Pancreatic Neuroendocrine Neoplasms: Practical Approach to Diagnosis, Classification, and Therapy. Stefano LR, Fausto S (eds.) Springer International Publishing, Switzerland, pp81-87, 2015.

8. Becker SW, Kahn D and Rothman S: Cutaneous manifestations of internal malignant tumors. Arch Dermatol Syphilol 45: 1069-1080, 1942.

9. McGavran MH, Unger RH, Recant L, Polk HC, Kilo C and Levin ME: A glucagon-secreting alpha-cell carcinoma of the pancreas. N Engl J Med 274: 1408-1413, 1966.

10. Wilkinson DS: Necrolytic migratory erythema with pancreatic carcinoma. Proc R Soc Med 64: 1197-1198, 1971.

11. Kindmark H, Sundin A, Granberg D, Dunder K, Skogseid B, Janson ET, Welin S, Oberg K and Eriksson B: Endocrine pancreatic tumors with glucagon hypersecretion: A retrospective study of 23 cases during 20 years. Med Oncol 24: 330-337, 2007.

12. PubMed [Internet]. Bethesda (MD): National Library of Medicine (US). [1946]-[cited 2016 January 23]. Available from: https://www.ncbi.nlm.nih.gov/pubmed/

13. Papotti M, Bongiovanni M, Volante M, Allìa E, Landolfi S, Helboe L, Schindler M, Cole SL and Bussolati G: Expression of somatostatin receptor types 1-5 in 81 cases of gastrointestinal and pancreatic endocrine tumors. A correlative immunohistochemical and reverse-transcriptase polymerase chain reaction analysis. Virchows Arch 440: 461-475, 2002.

14. Lepage C, Rachet B and Coleman MP: Survival from malignant digestive endocrine tumors in England and Wales: A population-based study. Gastroenterology 132: 899-904, 2007. 
15. McGevna L and Tavakkol Z: Images in clinical medicine. Necrolytic migratory erythema. N Engl J Med 362: e1, 2010.

16. McGevna L, McFadden D, Ritvo $\mathrm{J}$ and Rabinowitz T: Glucagonoma-associated neuropsychiatric and affective symptoms: Diagnostic dilemmas raised by paraneoplastic phenomena. Psychosomatics 50: 548-550, 2009.

17. Remes-Troche JM, Garcia-de-Acevedo B, Zuñiga-Varga J, Avila-Funes A and Orozco-Topete R: Necrolytic migratory erythema: A cutaneous clue to glucagonoma syndrome. J Eur Acad Dermatol Venereol 18: 591-595, 2004.

18. Pujol RM, Wang CY, el-Azhary RA, Su WP, Gibson LE and Schroeter AL: Necrolytic migratory erythema: Clinicopathologic study of 13 cases. Int J Dermatol 43: 12-18, 2004.

19. Johnson DS, Coel MN and Bornemann M: Current imaging and possible therapeutic management of glucagonoma tumors: A case report. Clin Nucl Med 25: 120-122, 2000.

20. Halvorson SA, Gilbert E, Hopkins RS, Liu H, Lopez C, Chu M, Martin M and Sheppard B: Putting the pieces together: Necrolytic migratory erythema and the glucagonoma syndrome. J Gen Intern Med 28: 1525-1529, 2013.

21. Alkemade JA, van Tongeren JH, van Haelst UJ, Smals A, Steijlen PM and van de Kerkhof PC: Delayed diagnosis of glucagonoma syndrome. Clin Exp Dermatol 24: 455-457, 1999.

22. Kimbara S, Fujiwara Y, Toyoda M, Chayahara N, Imamura Y, Kiyota N, Mukohara T, Fukunaga A, Oka M, Nishigori C and Minami H: Rapid improvement of glucagonoma-related necrolytic migratory erythema with octreotide. Clin J Gastroenterol 7: 255-259, 2014

23. Chang-Chretien K, Chew JT and Judge DP: Reversible dilated cardiomyopathy associated with glucagonoma. Heart 90: e44, 2004.

24. Demir OM, Paschou SA, Ellis HC, Fitzpatrick M, Kalogeropoulos AS, Davies A, Thompson J, Davies SW and Grapsa J: Reversal of dilated cardiomyopathy after glucagonoma excision. Hormones (Athens) 14: 172-173, 2015.

25. Gaiser CA and Dhawan N: Paradoxical presentation of glucagonoma with delayed onset of necrolytic migratory erythema. Am J Med 128: e1-e2, 2015.

26. Beattie PE, Fleming CJ, Evans AT, Sheppard DG, Leese GP, Dow E and Tait IS: Glucagonoma syndrome presenting as psoriasis. QJM 95: 834-835, 2002.

27. Shyr YM, Su CH, Lee CH, Wu CW and Lui WY: Glucagonoma syndrome: A case report. Zhonghua Yi Xue Za Zhi (Taipei) 62: 639-643, 1999.

28. Nightingale KJ, Davies MG and Kingsnorth AN: Glucagonoma syndrome: Survival 24 years following diagnosis. Dig Surg 16: 68-71, 1999.

29. Recant L, Perrino PV, Bhathena SJ, Danforth DN Jr and Lavine RL: Plasma immunoreactive glucagon fractions in four cases of glucagonoma: Increased 'large glucagon-immunoreactivity’. Diabetologia 12: 319-326, 1976.
30. Kitamura Y, Sato M, Hatamochi A and Yamazaki S: Necrolytic migratory erythema without glucagonoma associated with hepatitis B. Eur J Dermatol 15: 49-51, 2005.

31. Technau K, Renkl A, Norgauer J and Ziemer M: Necrolytic migratory erythema with myelodysplastic syndrome without glucagonoma. Eur J Dermatol 15: 110-112, 2005.

32. Yamashita S, Tanaka N, Takahashi M, Nagai M, Furuya T, Suzuki Y and Nomura Y: Pancreatic insulinoma combined with glucagon positive cell: A case report. World J Gastrointest Surg 5: 68-72, 2013.

33. Lolis MS, Krishtul A, Vidal C, Shim-Chang H, Phelps R and Lebwohl M: Necrolytic migratory erythema associated with a metastatic neuroendocrine tumor. Cutis 87: 78-80, 2011.

34. Adams DR, Miller JJ and Seraphin KE: Glucagonoma syndrome. J Am Acad Dermatol 53: 690-691, 2005.

35. Schwartz RA: Glucagonoma and pseudoglucagonoma syndromes. Int J Dermatol 36: 81-89, 1997.

36. Miller HC, Kidd M, Modlin IM, Cohen P, Dina R, Drymousis P, Vlavianos P, Klöppel G and Frilling A: Glucagon receptor gene mutations with hyperglucagonemia but without the glucagonoma syndrome. World J Gastrointest Surg 7: 60-66, 2015.

37. Glueck CJ, Phillips HG, Cameron D and Wang P: Estrogen replacement in a protein $\mathrm{S}$ deficient patient leads to diarrhea, hyperglucagonemia, and osteonecrosis. JOP 2: 323-329, 2001.

38. Vanderlan WB, Zhang Z and Abouljoud MS: Duodenal enteroglucagonoma revealed by differential comparison of serum and tissue glucagon reactivity with Siemens' Double Glucagon Antibody and DakoCytomation's Polyclonal Rabbit Anti-Human Glucagon: A case report. J Med Case Rep 4: 178, 2010.

39. Plöckinger U, Rindi G, Arnold R, Eriksson B, Krenning EP, de Herder WW, Goede A, Caplin M, Oberg K, Reubi JC, et al: Guidelines for the diagnosis and treatment of neuroendocrine gastrointestinal tumours. A consensus statement on behalf of the European Neuroendocrine Tumour Society (ENETS). Neuroendocrinology 80: 394-424, 2004.

40. Melen-Mucha G, Lawnicka H, Kierszniewska-Stepien D, Komorowski J and Stepien H: The place of somatostatin analogs in the diagnosis and treatment of the neuoroendocrine glands tumors. Recent Pat Anticancer Drug Discov 1: 237-254, 2006.

41. Fernández-Cruz L, Blanco L, Cosa R and Rendón H: Is laparoscopic resection adequate in patients with neuroendocrine pancreatic tumors? World J Surg 32: 904-917, 2008.

42. Sarmiento JM, Que FG, Grant CS, Thompson GB, Farnell MB and Nagorney DM: Concurrent resections of pancreatic islet cell cancers with synchronous hepatic metastases: Outcomes of an aggressive approach. Surgery 132: 976-983, 2002.

43. Kindmark H, Sundin A, Granberg D, Dunder K, Skogseid B, Janson ET, Welin S, Oberg K and Eriksson B: Endocrine pancreatic tumors with glucagon hypersecretion: A retrospective study of 23 cases during 20 years. Med Oncol 24: 330-337, 2007. 